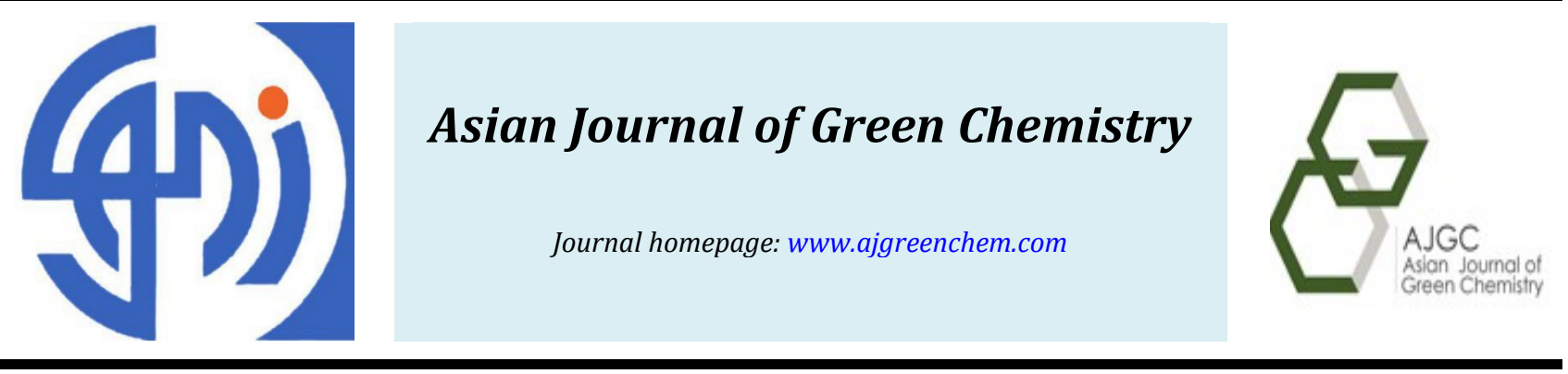

Original Research Article

\title{
Bioactive principle loaded gold nanoparticles as potent anti-melanoma agent: green synthesis, characterization, and in vitro bioefficacy
}

\author{
Saurabh Yadava, Mukti Sharmaa, Narayan Ganesh ${ }^{b}$, Shalini Srivastavaa, Man \\ Mohan Srivastavaa,* \\ a Department of Chemistry, Faculty of Science, Dayalbagh Educational Institute, Dayalbagh, Agra-282005, India \\ b Jawaharlal Nehru Cancer Hospital \& Research Center, Bhopal-462001, India
}

\begin{tabular}{|c|c|}
\hline ARTICLE INFORMATION & ABSTRACT \\
\hline $\begin{array}{l}\text { Received: } 3 \text { October } 2018 \\
\text { Received in revised: } 3 \text { November } 2018 \\
\text { Accepted: } 3 \text { November } 2018 \\
\text { Available online: } 22 \text { January } 2019 \\
\text { DOI: } 10.33945 / \text { SAMI/AJGC.2019.4.6 } \\
\text { KEYWORDS } \\
\text { Madhuca longifolia } \\
\text { Anti-melanoma bioefficacy } \\
\text { Bioactive principle } \\
\text { Enhancement in bioefficacy } \\
\text { F@AuNp }\end{array}$ & $\begin{array}{l}\text { This work discusses the presence of significant anti-melanoma bioefficacy in } \\
\text { the native bark ethanolic extract ( } 65.15 \%) \text { of the plant Madhuca longifolia. A } \\
\text { family of seven flavonoids was ascertained in the bark ethanolic extract of the } \\
\text { target plant using HPLC-ESI-QTOF-MS analysis as bioactive } \\
\text { constituents. Statistically, significant (p<0.05) enhancement in the anti- } \\
\text { melanoma bioefficacy (85.15\%) was successfully attempted, reaching near to } \\
\text { the level of reference (Cyclophosphamide drug) using bioactive principle } \\
\text { (flavonoid) loaded gold nanoparticles (F@AuNp). In vitro anti-melanoma } \\
\text { bioefficacy was measured against two melanoma cell lines (B16F10 and } \\
\text { A375) using MTT and SRB bioassays. The native bark extract and } \\
\text { F@AuNp did not show any toxicity towards the normal lymphocyte cells, } \\
\text { highlighting their safe and non-toxic nature. The pathway of observed anti- } \\
\text { melanoma efficacy of (F@AuNp) was discussed based on our experimental } \\
\text { findings on percent inhibition in mice and human melanoma cell lines, } \\
\text { production of intracellular reactive oxygen species, the release of nitric oxide, } \\
\text { and increase caspase-3 activities. The native bark extract of the plant } M \text {. } \\
\text { longifolia and its bioactive principle loaded gold nanoparticles possess bright } \\
\text { prospects for the development of complimentary herbal nanomedicine for } \\
\text { scaling-up the anti-melanoma bioefficacy. } \\
\text { C } 2019 \text { by SPC (Sami Publishing Company), Asian Journal of Green } \\
\text { Chemistry, Reproduction is permitted for noncommercial purposes. }\end{array}$ \\
\hline
\end{tabular}




\section{Graphi cal Abstract}

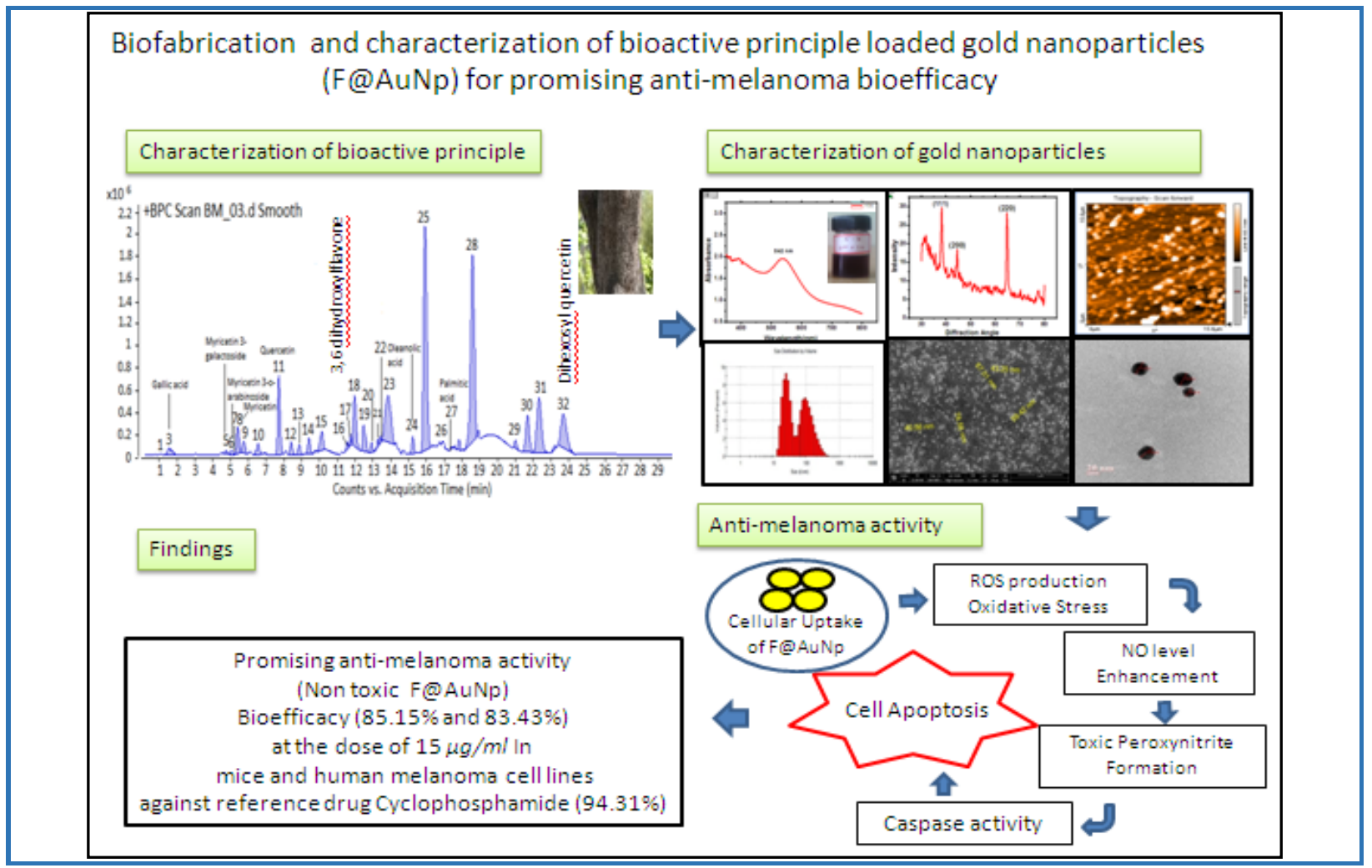

\section{Introduction}

World health organization has reported that 1,32,000 new cases are being diagnosed worldwide every year [1, 2]. Majority of skin cancers are basal cell carcinoma, squamous cell carcinoma, and malignant melanoma $[3,4]$. The incidence of melanoma is normally caused by ultraviolet radiations from sunlight triggering mutations to malignant tumours through unrepaired DNA damage [5]. Melanoma is a common skin cancer if recognized at an early stage and almost curable, otherwise it will become hard to tackle. Surgery, chemotherapy, and radiotherapy methods are used for treating the skin cancer. These methods are not only expensive but also may results in several side effects and drug resistance [6]. The resistance against conventional drugs heavily hampers the therapeutic efficiency, resulting in a high repetition rate of therapeutic failure [7]. It necessities the development of alternative effective treatments. Recently, the use of medicinal plants has gained considerable attention [8-10].

Medicinal plants are the rich source of bioactive compounds used in modern medicines as nutraceuticals, food supplements, pharmaceutical intermediates, and template molecule [11]. More than $60 \%$ of the anti-cancerous drugs are made of plant origin [12]. The plant-based anti-cancerous drugs incorporate vinblastine, vincristine, topotecane, and etoposide. However, such bio-molecules 
have shown limited bioefficacy. Research efforts [13-15] are made to meet out such objectives committing synthetic modifications on the plant bioactive functional groups [16-18]. Recently, the plant-based nanomaterials have been widely used for improving the bioactive functionalities [19, 20]. The herbal moieties are more biocompatible compared with that of the conventional therapeutic carriers [21, 22]. Nanobiotechnology can be seen in future of site-specific tumour therapy, radiotherapy, gene therapy, and chemotherapy. Looking at the speed of advancement of nanomedicine, particularly the utilization of various nanoparticles in prevention, diagnosis, and treatment of a complex disease like cancer, one can predict that this innovative technology will be on our doorstep soon. This enthusiasm has motivated the research trend towards the loading of bioactive principle on to noble metal nanoparticles to be used in cancer therapy.

The present communication, for the first time, has explored the presence of anti-melanoma bioefficacy in the bark ethanolic extract of the plant M. longifolia, and as bioactive components (A family of seven flavonoids). Another focus of the work is towards the enhancement in the antimelanoma bioefficacy of native bark extract using bioactive principle (Flavonoids) loaded gold nanoparticles (F@AuNp). Biofabrication of F@AuNp is carried out in a single step green process followed by its exhaustive characterization. In vitro bioassays (MTT and SRB) are carried out on normal lymphocytes and two melanoma (mice; B16F10 and human; A375) cell lines for exploring any toxicity for the human being and anti-melanoma bioefficacy against cell lines. Madhuca longifolia (Mahua), one of the most important wild Indian forest plant (Sapotaceae family) has been highly popular as folk remedies [23-25]. Its pharmacological applications as the tribal remedy for skin problems such as itching, swelling, and inflammation has motivated us to explore its antimelanoma bioefficacy.

\section{Experimental}

\section{Collection, authentication, and microwave-ultrasound assisted extraction}

The fresh bark of plant $M$. longifolia of the single population was collected from the village Rajaborari (Madhya Pradesh), India. The authentication of the plant material was carried out by the Taxonomy Division, Department of Botany, Dayalbagh Educational Institute, Dayalbagh, Agra, India, where a sample was deposited with the voucher specimen number DEI/DB/DH/2015-073. The bark portion was cleaned, dried, and then powdered. Microwave-assisted extraction of the bark was carried out in an aqueous alcoholic solution at $200 \mathrm{~W}$ for $5 \mathrm{~min}$. The extract was subjected to an ultrasonic bath for $30 \mathrm{~min}$ at room temperature. The extract was concentrated by rota-vapour distillation and finally dried by the purging nitrogen. 
Isolation and characterization of bioactive principle (flavonoids)

Dried fraction (10 gm) was subjected to column chromatographic separation [Length $120 \mathrm{~cm}$; diameter $4 \mathrm{~cm}$; mesh 60; stationary phase; silica gel (125 gm)] and eluted with $\mathrm{CH}_{3} \mathrm{OH} / \mathrm{CHCl}_{3}(3: 7)$. After the removal of solvent, a brown mass was obtained. The brown mass fraction was subjected to HPLC-ESI-QTOF-MS mass spectra to characterize the flavonoidal compounds. HPLC-ESI-QTOF-MS analysis was performed on quadrupole time-of-flight (QTOF) mass spectrometer connected with the Agilent 1200-HPLC system via dual electrospray ionization interface (Agilent Technologies, USA). HPLC separation was carried out using a poroshell 120 EC-C18 column (50 mm× $4.6 \mathrm{~mm}, 2.7 \mu$ ). The mobile phase consisted of $0.1 \%$ formic acid solution (A) and methanol (C) with flow rate of 0.5 $\mathrm{mL} / \mathrm{min}$ under the gradient program of 30 to $90 \%$ (C) for initial $10 \mathrm{~min}$, then $90 \%$ (C) from 10 to 20 min, 90 to 30\% (C) from 20 to $25 \mathrm{~min}, 30 \%$ (C) from 25 to $30 \mathrm{~min}$. Mass spectrometric analysis was performed in positive ESI mode. The resolving power of the QTOF analyzer was set above 10,000 (FWHM). The spectra were acquired within a mass range of $m / z$ 100-1500. Capillary temperature was set at $350^{\circ} \mathrm{C}, \mathrm{N}_{2}$ nebulizer pressure of $40 \mathrm{psi}$, and gas flow rate of $10 \mathrm{~L} / \mathrm{min}$.

\section{Biofabrication and characterization of F@AuNp}

The optimized experimental conditions of the biofabrication of gold nanoparticles were as follows: flavonoidal content $(1 \mathrm{~mL}, 0.5 \mathrm{mg} / \mathrm{mL})$, sodium tetrachloroaurate dihydrate solution $(2 \mathrm{~mL}$, $1 \mathrm{mM}$ ) and sonication (15 $\mathrm{min}, 20 \mathrm{KHz}$ ) at $\mathrm{pH}$ 4. The optical properties (UV-vis spectrophotometer, Lab India, India), particles size and zeta potential (Zetasizer, nano ZS90 model Malvern, Germany), miller indices (XRD, Bruker AXS D8 advance, Germany), morphology (FE-SEM, Nova Nano FE-SEM 450, Netherland), surface roughness (AFM, nanosurf easyscan V 1.8, Switzerland), and elemental composition (EDX, tecnai G2 T 20 ST, Germany) of F@AuNp were evaluated.

\section{Cell culture}

\section{Mice melanoma (B16F10) and human melanoma (A375) cell lines}

The mice melanoma (B16F10) and human melanoma (A375) cell lines were purchased from the National Centre for Cell Science, Pune, India, and grown in Dulbecco's Modified Eagle's Medium containing antibiotics, $L$-glutamine ( $2 \mathrm{mM}$ ), fetal bovine serum $(10 \%)$. Cells were kept at $37^{\circ} \mathrm{C}$, with the relative humidity of $100 \%, \mathrm{CO}_{2}(5 \%)$, and air (95\%). The culture medium was changed thrice in a week. The single cell suspension was made using the trypsin-ethylene diamine tetra acetic acid. The cell suspension was diluted with media containing FBS (5\%) to obtain the final density of $1 \times 10^{5}$ cells/mL. Ninety-six-well plate was seeded (10,000 cells/well) and incubated in the $\mathrm{CO}_{2}$ incubator. 
Cells were treated (In triplicate) with different concentrations of the test samples after $24 \mathrm{~h}$ against control. Cyclophosphamide that has been frequently used for the treatment of melanoma cancer, was used as a standard chemotherapeutic drug.

\section{Isolation of lymphocytes}

Defibrinated blood (2 mL) and Ficoll-Paque PLUS (2.5 mL) was mixed and centrifuged for 30 min and the upper layer was removed leaving the lymphocyte layer undisturbed at the interface. The lymphocyte layer was transferred to a clean tube and further centrifuged for $30 \mathrm{~min}$. The balanced salt solution was added and centrifuged again. The supernatant was discarded and suspension of the lymphocytes was mixed with RPMI-1640 medium. Few drops of PHA (mitogen) were added and incubated for $24 \mathrm{~h}$ in a $\mathrm{CO}_{2}$ incubator.

\section{Cell viability and anti-melanoma bioefficacy (MTT \& SRB bioassay)}

In vitro cell viability and anti-melanoma bioefficacy of fabricated (F@AuNp) were examined against the lymphocytes and two melanoma (mice; B16F10 and human; A375) cell lines respectively using standard procedures [26, 27].

\section{Intracellular reactive oxygen species}

Mice melanoma cell lines were treated with $(20 \mu \mathrm{L})$ of experimentally measured $\mathrm{IC}_{50}$ of F@AuNp $(13.19 \mu \mathrm{g} / \mathrm{mL})$ and incubated for $24 \mathrm{~h}$. Cells were washed with fresh media and incubated with 2, 7 di-chloro dihydro fluorescein diacetate $(1 \mu \mathrm{g} / \mathrm{mL})$ for $30 \mathrm{~min}$ at $37^{\circ} \mathrm{C}$. DCF fluorescence was used to determine the excitation at $485 \mathrm{~nm}$ and emission at $520 \mathrm{~nm}$ using a cary eclipse fluorescence spectrophotometer [28].

\section{Nitric oxide release assay}

$50 \mu \mathrm{L} /$ well of serum was treated with $20 \mu \mathrm{L}$ of experimentally measured IC 50 of F@AuNp (13.19 $\mu \mathrm{g} / \mathrm{mL})$ and incubated for $24 \mathrm{~h}$. Griess reagent $(100 \mu \mathrm{L})$ was added and incubated at room temperature for $10 \mathrm{~min}$. Absorbance was recorded at $550 \mathrm{~nm}$ against the calibration curve of sodium nitrite. The level of nitric oxide was expressed as $\mu \mathrm{M} / \mathrm{mg}$ protein [29].

\section{Caspase-3 activity}




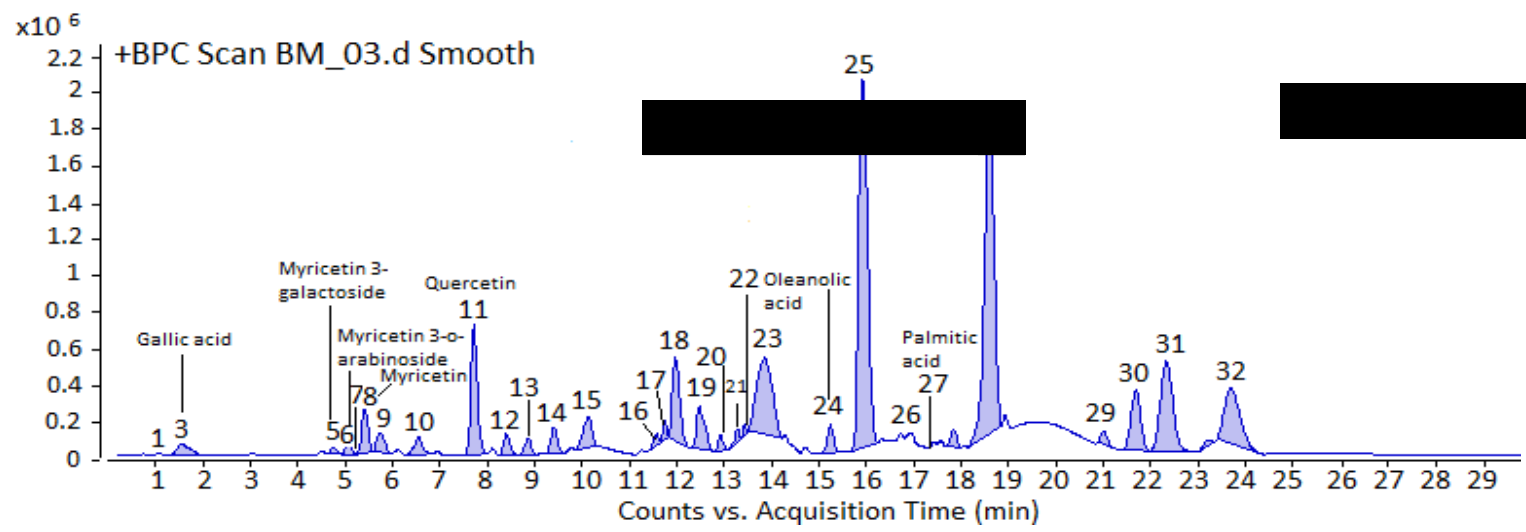

Figure 1. HPLC-ESI-QTOF-MS chromatogram depicting the presence of flavonoids
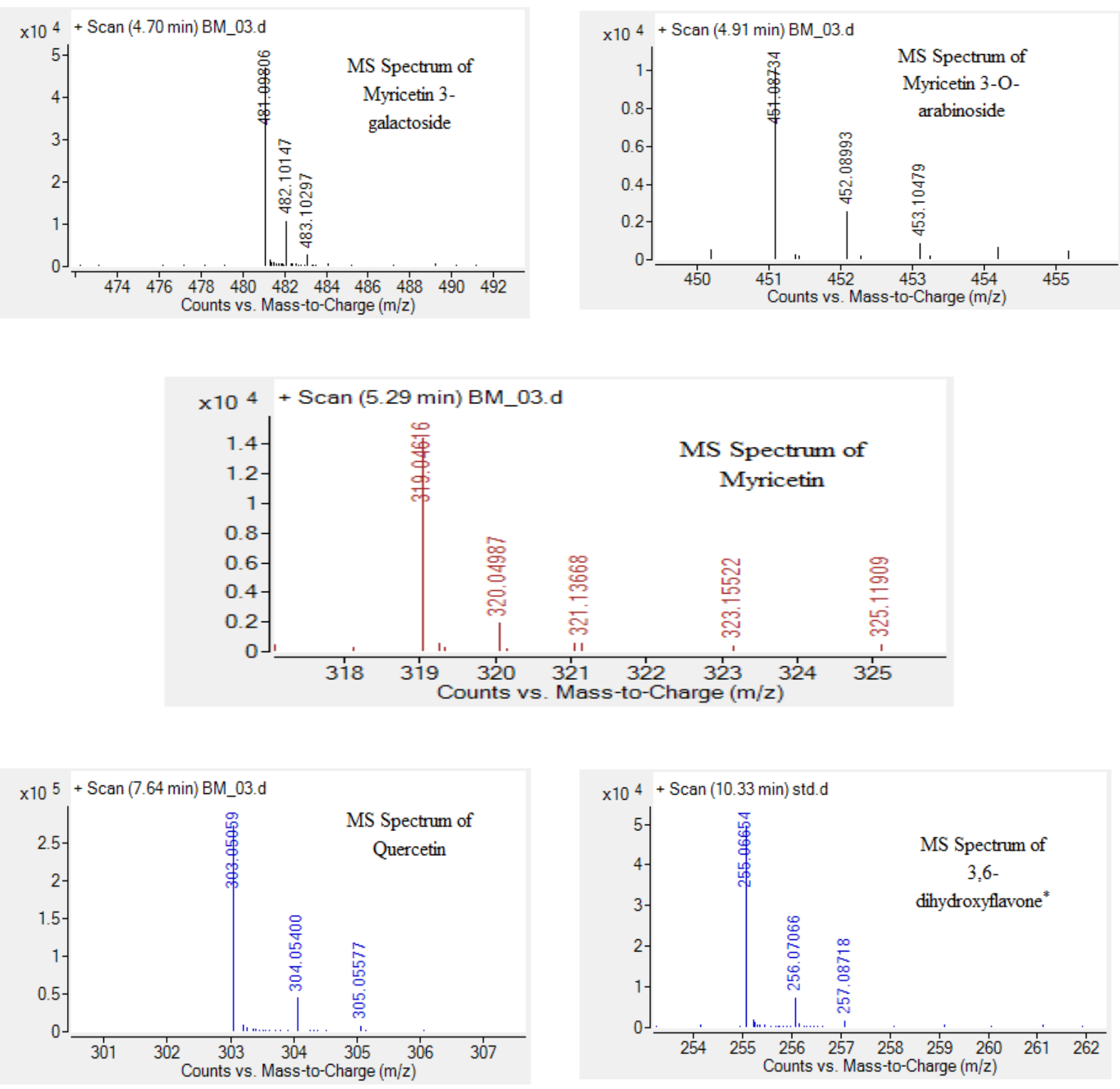


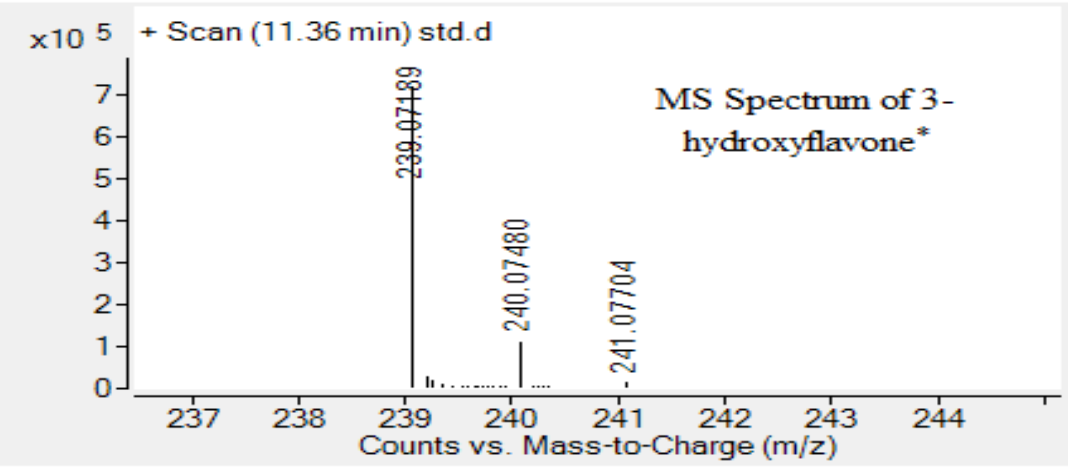

Figure 2. Mass fragmentation mode of flavonoids with their fragmentation pattern $(\mathrm{m} / \mathrm{z})$.

Caspase-3 activity in melanoma cells was assessed using a colorimetric caspase-3 assay kit [30]. Mice melanoma cells $\left(2 \times 10^{5} /\right.$ well $)$ were seeded in 96-well plates, treated with different concentrations of F@AuNp (0, 25, 50, 75 and $100 \mu \mathrm{g} / \mathrm{mL})$ and PBS-DMEM (10\%). Caspase-3 levels was measured using ELISA readers at $\lambda_{\max } 450 \mathrm{~nm}$ and the desired activity was calculated as fold increase over control sample.

\section{Statistical analysis}

All the experiments were performed in triplicate and the results were presented as mean \pm standard deviation. Statistical analysis was performed using one way-ANOVA (analysis of variance between the groups and within the group) followed by Tukey's test at $(\mathrm{p}<0.05)$ significance level.

\section{Results and Discussion}

\section{HPLC-ESI-QTOF-MS profile}

The use of various parts of the plant M. longifolia as popular folk medicine, particularly for skin related issues, implies the presence of important secondary metabolites in the plant [31, 32]. Among the secondary metabolites, polyphenolic flavonoids play important role in the antioxidant and in turn anti-cancer bioefficacy [33-36], which motivated us to explore the presence of flavonoids in the native bark extract of the plant $M$. longifolia in which the detailed phytochemical analysis is lacking.

HPLC-ESI-QTOF chromatogram (Figure 1) ascertained the presence of a family of following flavonoids. Myricetin 3-O-galactoside; $m / z 481.09$ (5), myricetin 3-0-arabinoside; $m / z 451.08$ (6), myricetin; $m / z 319.04$ (8), quercetin; $m / z 303.05$ (11), 3, 6 dihydroxyflavone; $m / z 255.06$ (15), dihydroquercetin; $m / z 301.21$ (23) and di-hexosyl-quercetin; $m / z 621.31$ (32) at retention time, 4.8 min, $4.9 \mathrm{~min}, 7.6 \mathrm{~min}, 10.1 \mathrm{~min}, 13.9$ and $23.6 \mathrm{~min}$, respectively. Other notable peaks of compounds like ascorbic acid $m / z 176.12$ (16), retinoic acid $m / z 300.43$ (17), stigma sterol $m / z 413.39$ (18), 
lucein $m / z 131.17$ (19), oleanolic acid $m / z 457.36$ (24), palmitic acid $m / z 257.24$ (27) were also found in addition to some unidentified peaks. Fragmentation pattern (count vs $\mathrm{m} / \mathrm{z}$ ) of each identified flavonoid has been summarized in (Figure 2).

The strong synergistic reduction potential of a family of flavonoids ( $-\mathrm{OH}$ groups), isolated from the bark of the plant M. longifolia was used for the biofabrication of F@AuNp. During fabrication, flavonoidal compounds undergo keto-enol form conversion, which led to the reduction of $\mathrm{AuCl}^{4-}$ ion to $\mathrm{Au}^{0}$ metal. Based on the ability of flavonoids forming a complex with metal ions [37], a tentative mechanism for the reduction of $\mathrm{Au}^{+3}$ by the flavonoids may be proposed (Scheme 1). The normal complexation sites are 3' \& 4' carbon position of the basic skeleton of flavonoids. Complexation at 3 and 4 -oxo group are also possible, discarding the possibility of complexation between 4-oxo and 5carbon atom. Further, the existence of possible steric hindrance of any complexation between 4-oxo and -OH group at 3-carbon atom can make the molecule unstable.

\section{Characterization of F@AuNp}

The biofabricated F@AuNp was evaluated using different analytical techniques, as depicted in Figure 3 and 4, and summarized in Table 1. Depending upon the size and shape of nanoparticles, UVvis spectra (Figure 3a) at characteristic surface plasma resonance band at $\lambda_{\max }=542 \mathrm{~nm}$ confirmed the formation of F@AuNp. X-ray diffraction pattern (Figure 3b) established lattice plane (111) as the most reactive (high atom density) transcendent crystallographic plane. Presence of some unassigned peaks can be ascribed to the crystallization of bioorganic phase [38]. Three dimensional (Figure 3c) and two-dimensional (Figure 3d) AFM images of F@AuNp were indicative of significant roughness of the surface. FE-SEM images of F@AuNp (Figure 3e) depicted mono layered well-dispersed shape, which facilitated the loading of secondary metabolites onto the particles.

TEM images (Figure 3f) showed the polydispersed size of the particles in a narrow range of 12.20$30.28 \mathrm{~nm}$. Light-coloured shade around the F@AuNp appeared in TEM image, was the indication of the coating of secondary metabolites (Flavonoids) on the nanoparticles. The measurement of zeta size (Figure 4a) revealed that the majority of particles lie in the range of 10-100 $\mathrm{nm}$ with an average size of $39.76 \mathrm{~nm}$. Zeta potential (Figure $4 \mathbf{b}$ ) confirmed the presence of high negative charge on the surface of the nanoparticles. The fact explained the repulsive forces among the particles keeping them in the nano state in the liquid phase, enhancing their stability. Finally, formation of F@AuNp was confirmed by the EDX elemental analysis (Figure 4c), exhibiting the presence of strong signals of $\mathrm{Au}$. Other peaks of $\mathrm{C}(1.45 \mathrm{KeV}), \mathrm{O}(8.12 \mathrm{KeV})$, and $\mathrm{N}(1.23 \mathrm{KeV})$ might have originated from the biomolecules. The peak of $\mathrm{Cu}(1.42 \mathrm{KeV})$, might be an artefact of the $\mathrm{Cu}$ grid on which sample was coated. 
<smiles>O=c1c(O)c(-c2cc(O)c(O)c(O)c2)oc2cc(O)ccc12</smiles>

flavonoid

$$
\begin{aligned}
3 \mathrm{~F} & \stackrel{2 \mathrm{H} / \text { molecule }}{\longrightarrow} 3 \mathrm{~F}+6 \mathrm{H}^{+}+6 \mathrm{e}- \\
2 \mathrm{Au}^{+3}+6 \mathrm{e}- & \longrightarrow 2 \mathrm{Au}^{\mathrm{O}}
\end{aligned}
$$<smiles>[R]Cc1ccc(O)c(O)c1</smiles>

Flavonoid moiety (Catechol moiety)

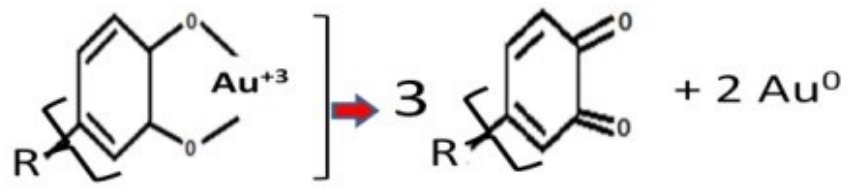

Oxidized flavonoid (quinone moiety)

Scheme 1.
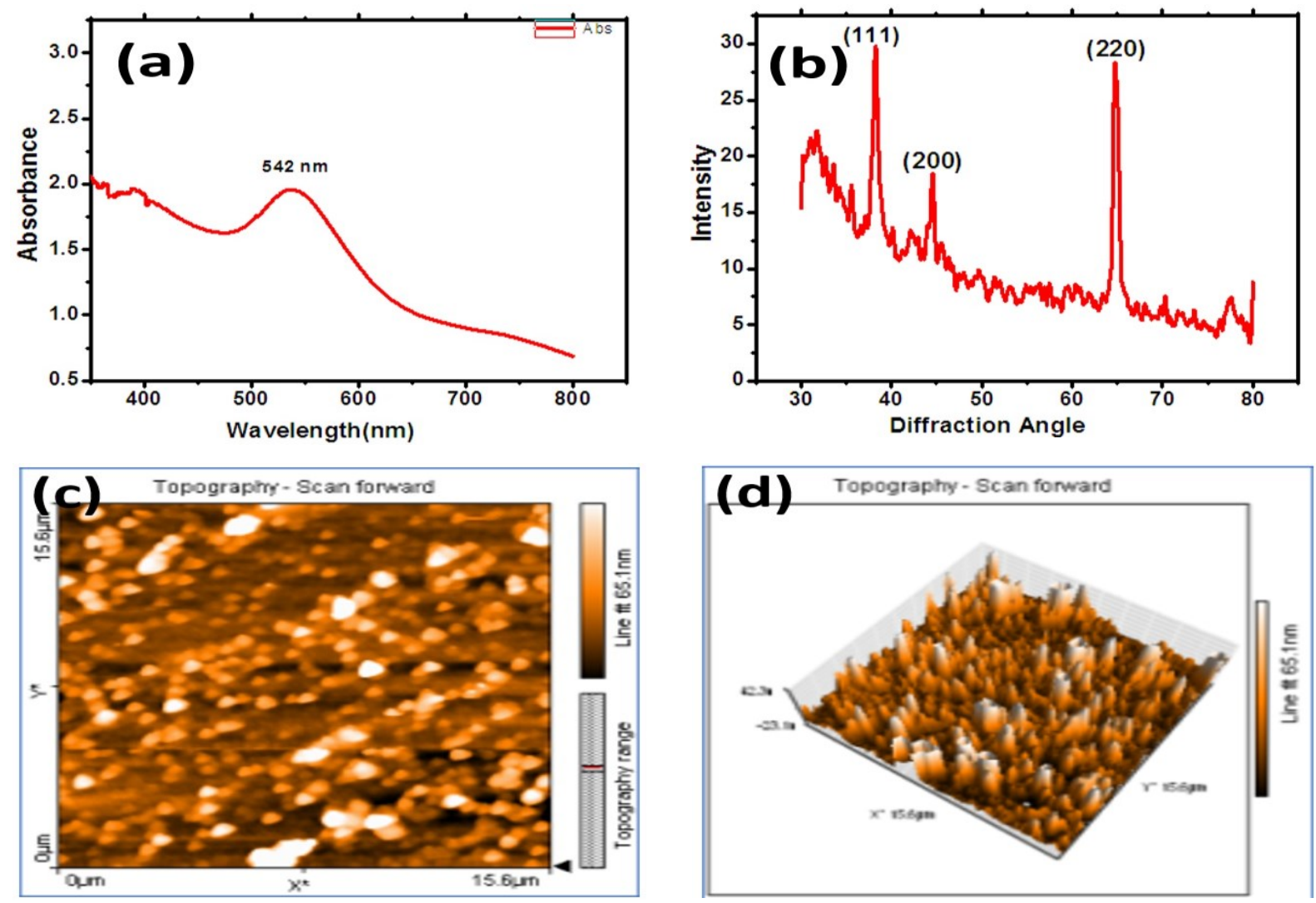

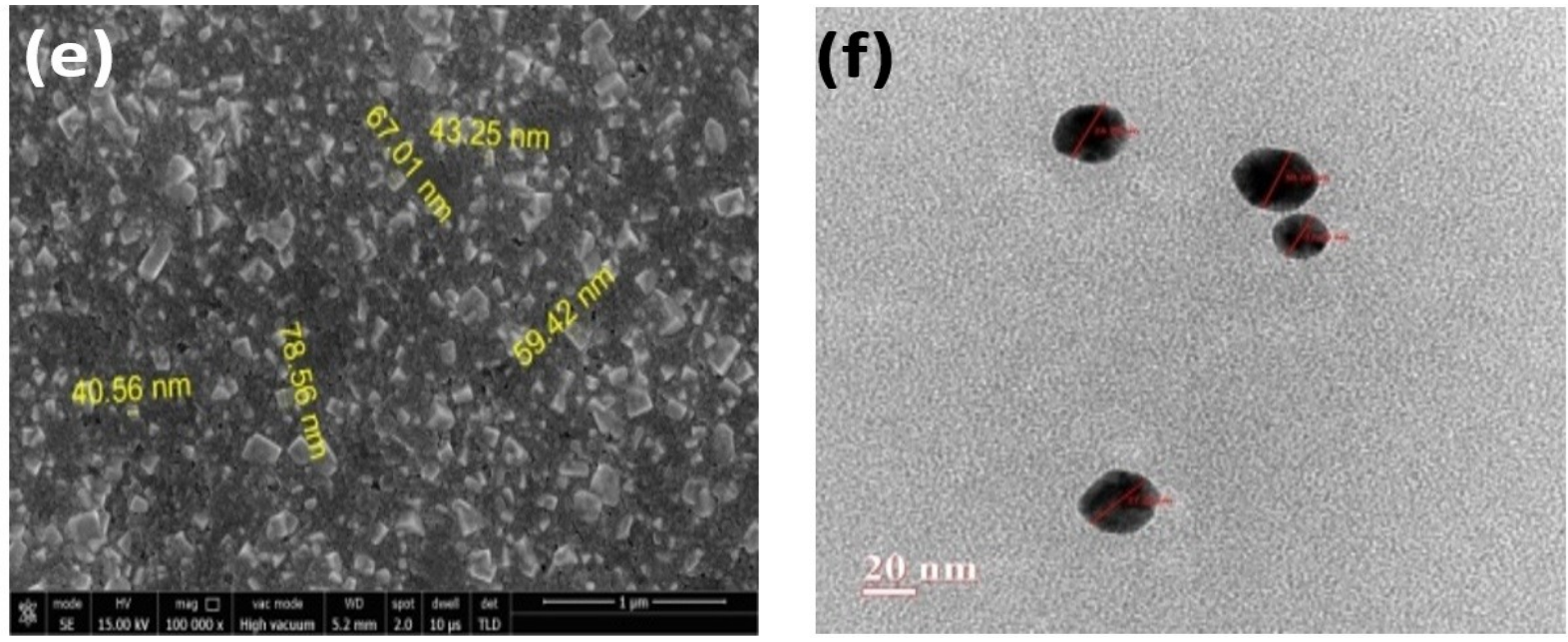

Figure 3. F@AuNp a) UV-vis spectra, b) XRD pattern, c \& d) AFM image, e) SEM micrograph, and f) TEM image
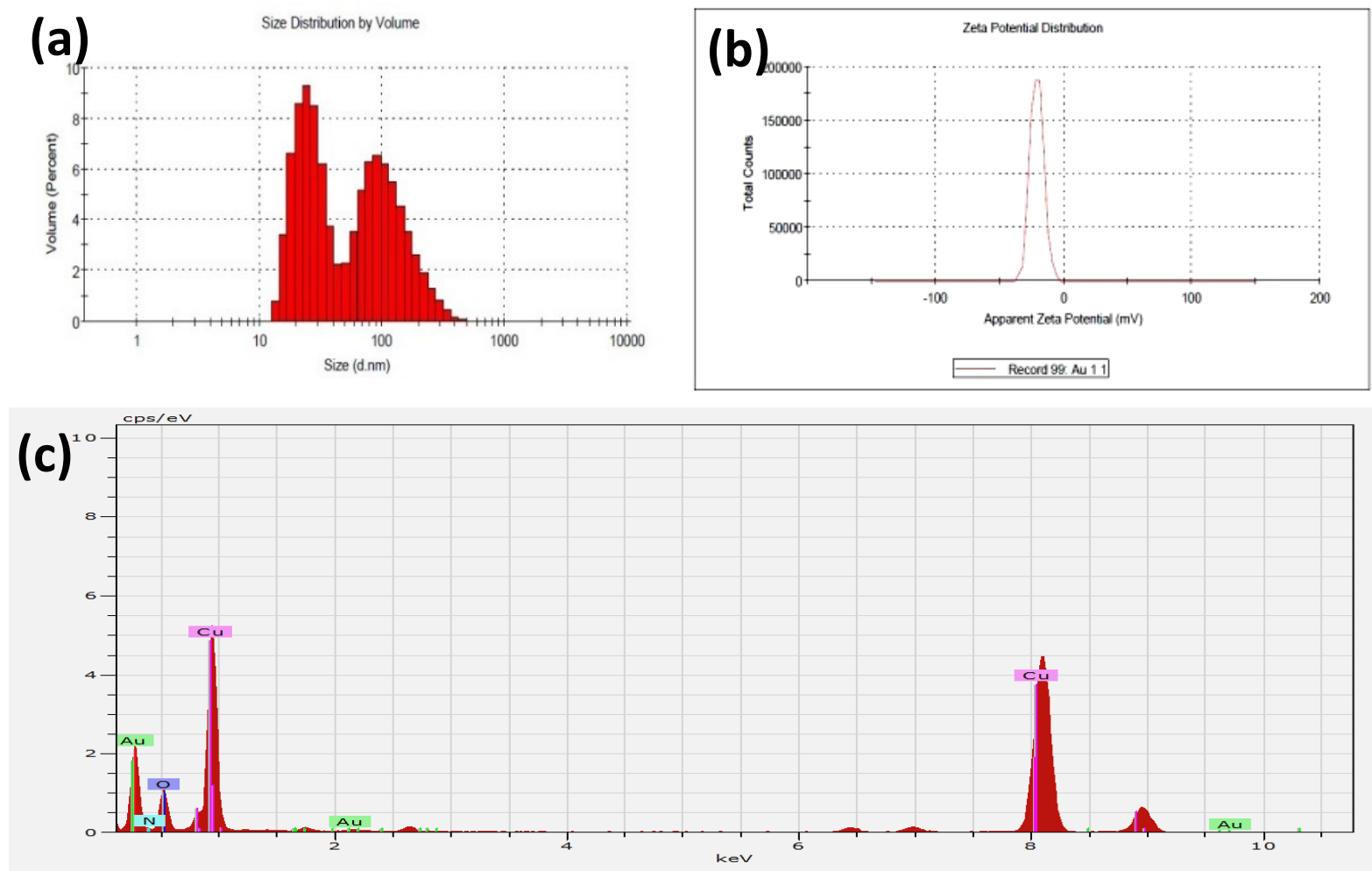

Figure 4. F@AuNp a) Zeta size, b) Zeta potential and c) EDX spectra

\section{Cell viability and anti-melanoma activity}

The native bark extract and F@AuNp did not show any noticeable cytotoxicity (Figure 5) towards the normal lymphocytes cells at the doses selected for the assessment of anti-melanoma bioefficacy. A significant correlation $\left(R^{2}=0.972\right)$ was observed in percent inhibition and different doses of native 
Table 1. The salient feature of the characterization of F@AuNp.

\begin{tabular}{|c|c|c|}
\hline Techniques & Observations & Findings \\
\hline UV-vis ${ }^{a}$ & $\lambda_{\max }=542 \mathrm{~nm}$ & Formation of F@AuNp \\
\hline $\mathrm{DLS}^{\mathrm{b}}$ & Asymmetric distribution in the & Average size $39.76 \mathrm{~nm}$ with poly \\
\hline (Zeta Size) & range (11.23 to $156.9 \mathrm{~nm})$ & dispersive index (0.238) \\
\hline DLS & Presence of negative charge & Zeta potential $(-20.7) \mathrm{mV}$ \\
\hline \multicolumn{3}{|l|}{ (Zeta potential) } \\
\hline \multirow[t]{2}{*}{$\mathrm{XRD}^{\mathrm{c}}$} & Diffraction peaks at positions & Indexed to (111), (200) and (220) \\
\hline & of $(2 \theta)$ at $38.2^{0}, 44.5^{0}$ and $64.7^{0}$ & having lattice face-centered cubic \\
\hline \multirow[t]{2}{*}{ FE-SEM d } & Cubic, triangular, and & Polydispersed layer \\
\hline & rectangular morphology & \\
\hline TEMe & Particles diameter & Particle size range $12.20-30.28 \mathrm{~nm}$ \\
\hline $\mathrm{AFM}^{\mathrm{f}}$ & The surface of nanoparticles & The average roughness of $14.18 \mathrm{~nm}$ \\
\hline \multirow[t]{2}{*}{ EDXg } & Peaks of $A u$ at $1.30,2.30$, and & Formation of $\mathrm{Au}$ nanoparticles along \\
\hline & $9.80 \mathrm{KeV}$ & with others elements $\mathrm{C}, \mathrm{O}, \mathrm{N}$ and $\mathrm{Cu}$ \\
\hline
\end{tabular}

a UV-vis: Ultra violet-visible spectroscopy

b DLS: Dynamic light scattering

cXRD: X-Rays Diffraction

${ }^{\mathrm{d}}$ FE-SEM: Field Emission Scanning Electron Microscopy

e TEM: Transmission electron microscopy

${ }^{\mathrm{f}}$ AFM: Atomic Force Microscopy

g EDX: Energy Dispersive X-rays

bark extract and F@AuNp for their cytotoxic potential against melanoma cell lines. This finding was noteworthy and revealed that the use of the native bark extract and F@AuNp would be safe and nontoxic towards normal lymphocytes cells. All the five groups were evaluated for their ability to inhibit the growth of mice melanoma (B16F10) and human melanoma (A375) cancer cell lines. Antimelanoma activity (In terms of percentage inhibition) was measured using the MTT and SRB bioassays (Table 2).

MTT bioassay that is used for the anti-proliferative assay [39] was considered for discussion. In general, enhancement in the percentage inhibition with increasing doses was observed in all the groups. Based on the maximum percent inhibition, the doses of the native bark extract, flavonoidal content, and F@AuNp were optimized as (65.31; $50 \mu \mathrm{g} / \mathrm{mL}, 75.14 ; 15 \mu \mathrm{g} / \mathrm{mL}$, and 85.15; $15 \mu \mathrm{g} / \mathrm{mL})$, respectively. The increased percentage inhibition $(75.14$ at $15 \mu \mathrm{g} / \mathrm{mL}$ ) compared to native bark 
extract (65.31 at $50 \mu \mathrm{g} / \mathrm{mL}$ ) signified the role of flavonoids as the possible bioactive component of the native bark extract of the plant $M$. longifolia. In addition, the bioactive active principle (Flavonoids) loaded gold nanoparticles (F@AuNp) exhibited an additional increase $(10.01 \%)$ in antimelanoma bioefficacy (85.15\%) compared to only flavonoid content. This supports the school of thoughts that bioactive principle loaded nanoparticles impart significant enhancement in the bioefficacy [40,41]. The biocompatibility, astonishing optical properties, high surface area to volume ratio (Nano sizing), and coating of medicinally important flavonoids on nanoparticles may be ascribed to the significant enhancement in anti-melanoma bioefficacy. The oxidized flavonoids (Quinone moiety) being electron deficient may impart free radical scavenging ability thus adding extra antioxidant properties. Resulting increased permeability in the cell membrane finally enhances deep penetration and drug uptake in tissues. The increased drug accumulation in the cancerous cell could largely inhibit the proliferation of the cancerous cell.

Table 2. In vitro percent inhibition in MTT, and SRB bioassays on mice melanoma(B16F10) and human melanoma (A375) cell line

\begin{tabular}{|c|c|c|c|c|}
\hline \multirow[t]{2}{*}{ Groups } & \multicolumn{2}{|c|}{ \% Inhibition (B16F10) } & \multicolumn{2}{|c|}{ \% Inhibition (A375) } \\
\hline & MTT & SRB & MTT & SRB \\
\hline Control (Gp1) & $1.25 \pm 0.45$ & $1.89 \pm 0.97$ & $1.25 \pm 0.45$ & $1.89 \pm 0.97$ \\
\hline \multicolumn{5}{|c|}{ Std. Drug $(\mu \mathrm{g} / \mathrm{mL})(\mathrm{Gp} 2)$} \\
\hline 10 & $67.36^{*} \pm 1.11$ & $63.54 * \pm 1.56$ & $65.86 * \pm 1.12$ & $65.45^{*} \pm 1.35$ \\
\hline 15 & $94.31 * \pm 1.21$ & $92.42^{*} \pm 1.54$ & $95.34 * \pm 1.24$ & $93.24 * \pm 1.44$ \\
\hline 20 & $97.13^{*} \pm 1.01$ & $94.67^{*} \pm 1.48$ & $97.23^{*} \pm 1.04$ & $94.89 * \pm 1.08$ \\
\hline \multicolumn{5}{|c|}{ Native bark extract $(\mu \mathrm{g} / \mathrm{mL})(\mathrm{Gp} 3)$} \\
\hline 25 & $49.39 * \pm 1.10$ & $46.34 * \pm 1.31$ & $51.01 * \pm 1.01$ & $48.04 * \pm 1.23$ \\
\hline 50 & $65.31^{*} \pm 1.12$ & $62.14^{*} \pm 1.14$ & $66.74 * \pm 0.99$ & $63.54 * \pm 1.01$ \\
\hline 100 & $66.92 * \pm 1.25$ & $63.34 * \pm 1.15$ & $67.22 * \pm 1.05$ & $64.34 * \pm 1.16$ \\
\hline \multicolumn{5}{|c|}{ Flavonoidal content $(\mu \mathrm{g} / \mathrm{mL})(\mathrm{Gp} 4)$} \\
\hline 10 & $63.12 * \pm 1.21$ & $61.32 * \pm 1.32$ & $64.45^{*} \pm 1.12$ & $62.45^{*} \pm 1.10$ \\
\hline 15 & $75.14^{*} \pm 1.22$ & $72.37^{*} \pm 1.45$ & $76.34^{*} \pm 1.03$ & $74.61 * \pm 1.16$ \\
\hline 20 & $77.42^{*} \pm 1.10$ & $75.39 * \pm 1.14$ & $78.31^{*} \pm 1.01$ & $76.15^{*} \pm 1.03$ \\
\hline \multicolumn{5}{|c|}{$\mathrm{F} @ A u N p(\mu \mathrm{g} / \mathrm{mL})(\mathrm{Gp} 5)$} \\
\hline 10 & $72.51^{*} \pm 1.12$ & $70.32 * \pm 1.41$ & $74.56^{*} \pm 1.41$ & $72.42^{*} \pm 1.34$ \\
\hline 15 & $85.15^{*} \pm 1.21$ & $81.39 * \pm 1.19$ & $86.34^{*} \pm 1.21$ & $83.43^{*} \pm 1.23$ \\
\hline 20 & $86.03^{*} \pm 1.51$ & $84.12 * \pm 1.15$ & $87.12 * \pm 1.05$ & $85.67 * \pm 1.48$ \\
\hline
\end{tabular}


The induced cellular apoptosis was supported by our experimental measurements on reactive oxygen species, nitric oxide production, and caspase-3 activity. ROS, depending on concentration, may discharge a dual role in living systems. The moderate concentration of ROS can promote cell proliferation, while excessive amount results into apoptosis via oxidative damage to lipids, proteins, and DNA. Therefore, maintenance of ROS homoeostasis becomes essential for the normal cell growth and survival [42]. The elevation in intracellular reactive oxygen species (57.7\%) in F@AuNp treated cells is significantly $(\mathrm{p}<0.05)$ higher compared with that of the control. Enhanced production of serum NO level (68.34\%) against control (Figure 6) in the case of F@AuNp treatment, is the indication of the elevation of ROS level. Nitric oxide reacts with superoxide to form toxic peroxynitrite (ONO0-) anion, which imparts anti-tumour activity [43]. Therefore, F@AuNp exposure might be attributed to the contribution of oxidative attack for cell death. Increase in caspase- 3 activity (Figure 7a) with the rise in the concentration of F@AuNp was observed in a dose dependent manner, which is responsible for the quick cell wall disruption, shrinking, and rupturing of the cell.

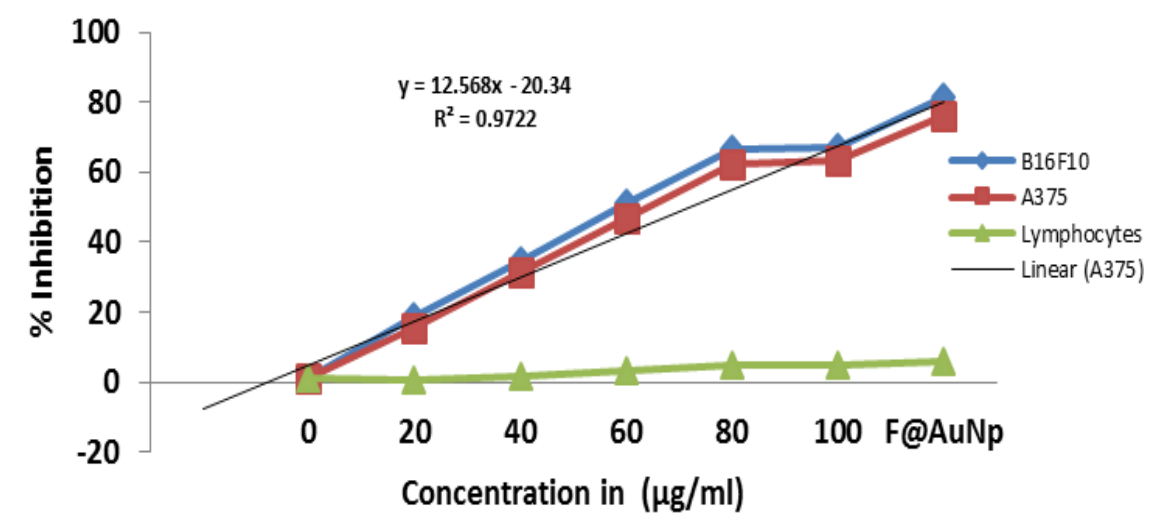

Figure 5. Cytotoxic potential of native bark extract and F@AuNp against mice melanoma (B16F10) human melanoma (A375) and lymphocytes cell lines

Figure 6. Level of Nitric oxide (NO) release of F@AuNp treated cell line

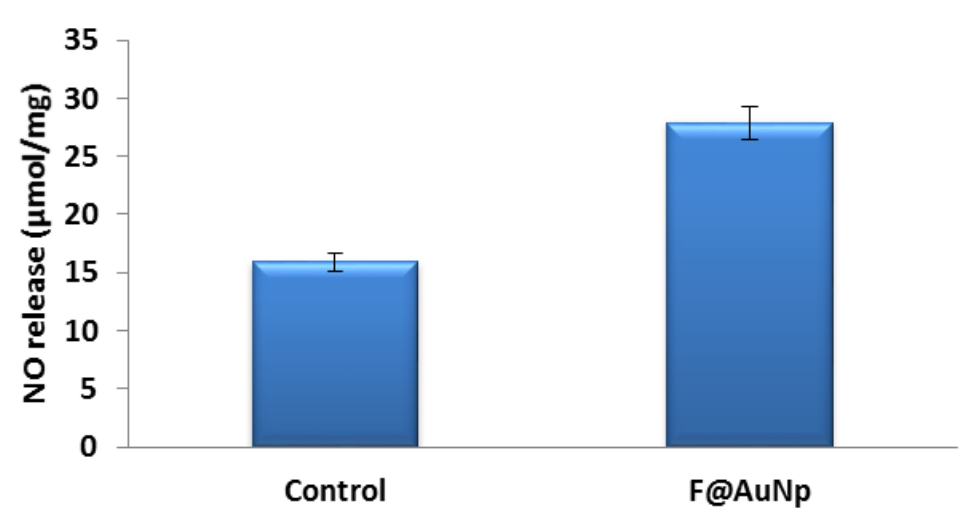




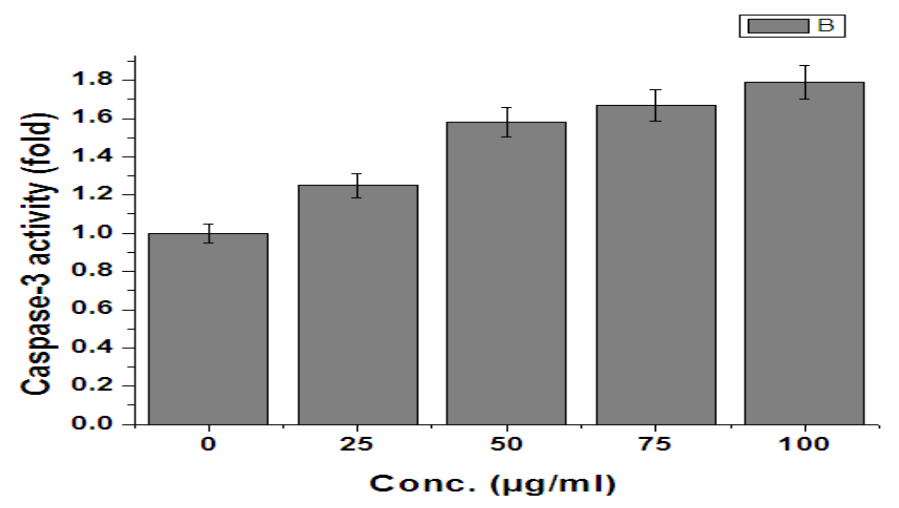

(b)

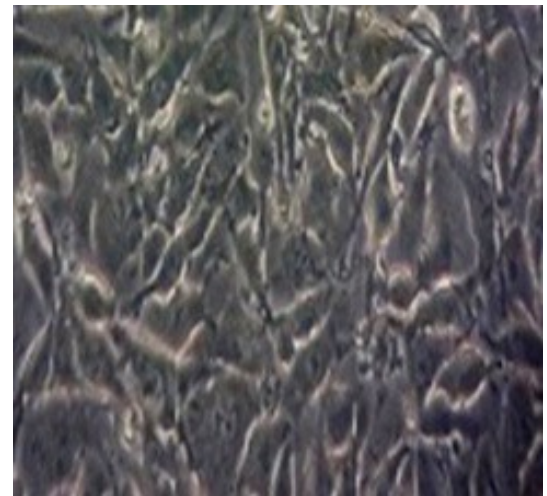

(c)

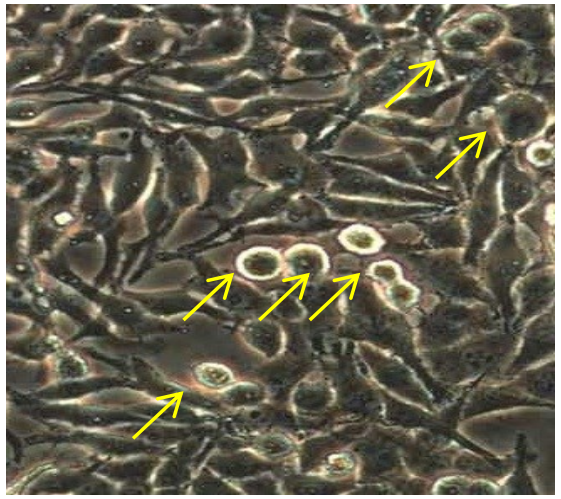

Figure 7. a) Dependence of F@AuNp on Caspase -3 activity, b) Control and, c) induced cellular change

\section{Conclusion}

This research study explores the significant anti-melanoma bioefficacy (65.15\%) in the native bark ethanolic extract of Madhuca longifolia. The excellent enhancement in the target anti-melanoma bioefficacy (85.15\%) was obtained using the bioactive principle loaded-gold nanoparticles (F@AuNp), reaching nearby to the level of reference drug cyclophosphamide (94.31\%). The presence of a family of seven flavonoids in the native bark extract of the plant $M$. longifolia was ascertained. The native bark extract and its F@AuNp were found to be non-toxic towards the normal lymphocytes. Bioactive component-loaded nanoparticles have valuable future in the controlled drug deliverytechnologies, providing maximum therapeutic efficacy and safety. The presence of promising anti-melanoma bioefficacy of F@AuNp prepared from the native bark extract of the plant $M$. longifolia may open a window for the development of effective herbal nano-medicine for treatment of the melanoma cancer.

\section{Disclosure Statement}

No potential conflict of interest was reported by the authors. 


\section{References}

[1]. Siegel R.L., Miller K.M., Jemal A. Cancer J. Clin., 2017, 67:7

[2]. Fitzmaurice C., Akinyemiju T.F., Lami Al., Rawaf F.H., Rawaf D.L. JAMA Oncol., 2018, 4:1553

[3]. Panda S. Indian J. Dermatol., 2010, 55:373

[4]. Feller L., Khammissa R.A.G., Kramer B., Altini M., Lemmer J. Head Face Med., 2016, 12:11

[5]. Chen J., Shao R., Zhang X. D., Chen C. Int. J. Nanomedicine., 2013, 8:2677

[6]. Chidambaram M., Manavalan R., Kathiresan K. J. Pharm. Pharm. Sci., 2011, 14:67

[7]. Lin G., Mi P., Chu C., Zhang J., Liu G. Adv. Sci., 2016, 3:1

[8]. Khoobchandani M., Ganesh N., Gabbanini S., Valgimigli L., Srivastava M.M. Fitoterapia, 2011, 82:647

[9]. Kalpna D.R., Mital J.K., Sumitra V.C. Academic Press of Elsevier, UK, 2013

[10]. Ahirwar R.P., Tripathi J., Singh R. Int. J. Appl. Res., 2017, 3:818

[11]. Cencic A., Chingwaru W. Nutrients, 2010, 2:611

[12]. Cragg G.M., Newman D.J.J. Ethnopharmacol., 2005, 100:72

[13]. Nobili A., Garattini S., Mannucci P.M. JOC., 2011, 1:28

[14]. Kundu P., Das M., Kalpalata Tripathy K., Sahoo S.K. ACS Chem. Neurosci., 2016, 7:1658

[15]. Bi D., Zhao L., Yu R., Li H., Guo Y., Wang X., Han M. Drug Delivery, 2018, 25:564

[16]. Ahmed S., Ahmad M., Swami B.L., Ikram S. J. Adv. Res., 2016, 7:17

[17]. Wink M. Medicine., 2015, 2:251

[18]. Kuppusamy P., Yusoff M.M., Maniam G.P., Govindan N. Saudi Pharm. J., 2016, 24:473

[19]. Sharma M., Yadav S., Srivastava M., Ganesh N., Srivastava S. Asian J. Nanosci. Mater., 2018, 1:244

[20]. He X., Hwang H.M. J. Food Drug Anal., 2016, 24:671

[21]. Bonifacio B.V., Silva P.B., Ramos M.A., Negri K.M., Bauab T.M., Chorilli M. Int. J. Nanomedicine., 2014, 9:1

[22]. Zhang M., Viennios E., Xu C., Merlin D. Tissue Barriers., 2016, 4:e1134415

[23]. Gaikwad R.D., Ahmed L., Khalid S., Swamy P. Pharma. Biol., 2009, 47:592

[24]. Akshatha K.N., Murthy S.M., Lakshmidevi N. IJLPR., 2013, 3:44

[25]. Jha D., Mazumder P.M. Asian Pacific J. Trop. Med., 2018, 11:9

[26]. Skenhan P., Storeng R., Scudiero D. J. Natl. Cancer Inst., 1990, 82:1107

[27]. Orellana E.A., Kasinski A.L. Bio Protoc., 2016, 6:21

[28]. Roy A., Ganguly A., BoseDasgupta S., Das B.B., Pal C., Jaisankar P., Majumder H.K. Mol. Pharm., 2008, 74:1292

[29]. Mahapatra S.K., Chakaraborty S.P., Das S., Roy S. Oxid. Med. Cell Longev., 2009, 2:222 
[30]. Mollick M.M.R., Bhowmick B., Mondal D., Maity D., Rana D., Dash S.K., Chattopadhyay S., Roy S., Sarkar J., Acharya K., Chakarborty M., Chattopadhyay D. RSC Adv., 2014, 4:37838

[31]. Patil S.A., Patil D.A. Nat. Prod. Rad., 2007, 6:2

[32]. Akshatha K.N., Murthy S.M., Lakshmidevi N. IJLPR., 2013, 3:44

[33]. Wojdylo A., Oszmianski J., Czemerys R. Food Chem., 2007, 105:940

[34]. Zhang Y.J., Gan R.Y., Li S., Zhou Y., Li A.N., Xu D.P., Li H.B. Molecules, 2015, 20:1

[35]. Madhe S., Bansal P., Srivastava M.M. Appl Nanosci., 2014, 4:153

[36]. Kasote D.M., Katyare S.S., Hegde M.V., Bae H. Int. J. Biol. Sci., 2015, 11:982

[37]. Osonga F.J., Yazgan I., Kariuki V., Luther D., Jimenez A., Le P., Sadik O.A. RSC Adv., 2016, 6:2302

[38]. Kumar B., Smita K., Cumbal L., Camacho J., Hernández-Gallegos E., Chavez-Lopez M.D.G., Grijalva M., Andrade K. Mater. Sci. Eng. C., 2016, 62:725

[39]. Haselsberger K., Peterson D.C., Thomas D.G., Darling J.L. Anticancer Drugs., 1996, 7:331

[40]. Grigalius I., Petrikaite V. Molecules, 2017, 22:1

[41]. Ballesta M.C.M., Izquierdo A.G., Viguera C.G., Perles R.D. Foods, 2018, 7:2

[42]. Kim J., Kim J., Bae J.S. Exp. Mol. Med., 2016, 48:1

[43]. Habib S., Ali A. Indian J. Clin. Biochem., 2011, 26:3

How to cite this manuscript: Saurabh Yadav, Mukti Sharma, Narayan Ganesh, Shalini Srivastava, Man Mohan Srivastava*. Bioactive principle loaded gold nanoparticles as potent anti-melanoma agent: green synthesis, characterization, and in vitro bioefficacy. Asian Journal of Green Chemistry, 3(4) 2019, 492-507. DOI: 10.33945/SAMI/AJGC.2019.4.6 